\title{
Argumentação linguística, enunciação e polifonia
}

\author{
Linguistic Argumentation, Utterance and Polyphony \\ Neiva Maria Tebaldi Gomes \\ Centro Universitário Ritter dos Reis/Laureate - Brasil
}

\begin{abstract}
Resumo: Este artigo faz uma incursão pela teoria polifônica apresentada por Oswald Ducrot em 1984, em O Dizer e o Dito, atualizada posteriormente por Marion Carel e Oswald Ducrot, e em constante revisão em estudos de Carel. Essa teoria é criada em oposição ao pressuposto da unicidade do sujeito falante. A partir de um estudo teórico-reflexivo, buscam-se, na teoria polifônica decorrente da Teoria da Argumentação na Língua, elementos que contribuam para a explicitação dos sentidos produzidos em textos acadêmicos, nos quais o locutor responsável pelo conteúdo acionado mobiliza uma diversidade de enunciadores. Para contextualizar o estudo, discutem-se conceitos fundantes, em pares distintivos: argumentação retórica e argumentação linguística, significação e sentido, frase e enunciado, locutor e enunciador. O potencial da teoria, para os fins aqui propostos, revela-se, mais especificamente, em duas indicações de análise semântica: uma relativa à "função textual" do conteúdo, outra ao "modo de aparição" desse conteúdo no enunciado.
\end{abstract}

Palavras-chave: Argumentação linguística; enunciado; polifonia

\begin{abstract}
This article makes an incursion through the polyphonic theory presented by Oswald Ducrot in 1984 in Dire et ne pas Dire, later updated by Marion Carel and Oswald Ducrot, and constantly being reviewed in Carel's studies. This theory is created in opposition to the presupposition of the unity of the subject who speaks. Through a theoretical and reflective study, elements that contribute to the explanation of the meanings produced in academic texts, in which the speaker responsible for the triggered content mobilizes a variety of enunciators, are sought in the polyphonic theory arising from the Argumentation Theory within Language. In order to contextualize the study, fundamental concepts are discussed in distinctive pairs: rhetorical argumentation and linguistic argumentation, significance and meaning, sentence and utterance, speaker and enunciator. The potential of the theory, for the purposes proposed herein, reveals itself, more specifically, in two indicatives of the semantic analysis: one relative to the "textual function" of the content, the other to the "appearance mode" of this content in the utterance.
\end{abstract}

Keywords: linguistic argumentation; utterance; polyphony

\section{Considerações gerais sobre a teoria}

Chamaremos, para simplificar, platônica a pesquisa de uma verdade absoluta, que exigiria que se ultrapassasse a linguagem, isto é, que se tentasse sair da Caverna (porque a verdadeira caverna, aquela que nos proíbe a relação com a realidade, aquela que nos obriga a viver no meio das sombras, é, para mim, a linguagem. (DUCROT)

O reconhecimento da impossibilidade de se estabelecer uma verdade única em estudos da linguagem, expresso por Ducrot, é certamente um sentimento compartilhado por todos os pesquisadores que se embrenham na verdadeira caverna que nos obriga a viver no meio das sombras, a linguagem. Essa sensação é ainda mais forte quando se faz opção por uma abordagem em constantes revisões, como a Teoria da Argumentação na Língua (ANL), proposta por Oswald Ducrot e JeanClaude Anscombre, e atualmente desenvolvida sob a denominação Teoria dos Blocos Semânticos (TBS) ${ }^{1}$ por Marion Carel e Oswald Ducrot.

\footnotetext{
A TBS foi a tese defendida por Marion Carel em 1992, posteriormente publicada em livro: L'Entrelacement argumentatif: lexique, discours e blocs sémantiques. Paris; Éditions Champion, 2011.
} 
A relação entre a ANL e a TBS é esclarecida por Ducrot (2006, p. 154), no artigo La sémantique argumentative peut-elle se réclamer de Saussure?, no qual ele diz que a concepção de semântica com que trabalha atualmente parece um prolongamento da Teoria da Argumentação na Língua, que ele elaborou com JeanClaude Anscombre. Diz tratar-se, mais precisamente, da Teoria dos Blocos Semânticos elaborada por Carel, teoria que ele vê como um aprofundamento e uma radicalização da Teoria da Argumentação na Língua, uma radicalização que lhe dá mais coerência em relação aos princípios que a constituem. Trata-se de uma teoria da argumentação essencialmente linguística, que procura descrever o sentido dos enunciados pela língua, sem apelar para estratégias extralinguísticas como o fazem os estudos clássicos da argumentação retórica.

No artigo Argumentação retórica e argumentação linguística (DUCROT, 2009, p. 25), Ducrot estabelece a distinção entre essas duas abordagens, inscrevendo-se, segundo ele mesmo, numa oposição sistemática ao otimismo retórico de Aristóteles e de seus seguidores. Já no início do artigo, ele esclarece que a palavra argumentação assume, na ANL e na TBS, um sentido diverso do habitual e isso, segundo ele, leva a muitos mal-entendidos. Esses mal-entendidos, na visão do autor, decorrem do fato de que se tem a tendência de ler as pesquisas que ele e seus colaboradores desenvolvem, dando à palavra argumentação o sentido que lhe é atribuído na abordagem identificada como argumentação retórica, definida como uma atividade verbal que visa fazer alguém crer em alguma coisa. Ducrot vê limitações nos estudos tradicionais dessa retórica. Entre outras, o fato de que, para levar alguém a fazer alguma coisa, a tradição só considera uma estratégia, nas suas palavras, "um pouco ingênua", que se apoia somente sobre um fazer crer que é bom fazê-lo. Quando, na verdade, diz ele, há outras formas de levar alguém a fazer algo. Do mesmo modo, ele vê como limitação desses estudos o fato de a persuasão exigir não apenas razões que constituem o que se chama o logos, uma transição racional entre as ideias, mas outras, como o desenvolvimento, no ouvinte, do desejo de crer verdadeiro (o pathos) e da confiança no orador, que deve dar de si uma imagem favorável (o ethos).

Assim, diferentemente da argumentação retórica, a argumentação linguística de que ele e Carel se ocupam considera a persuasão unicamente pela palavra, pelo discurso. Por essa perspectiva, o que Ducrot chama de argumentação linguística, ou abreviadamente, argumentação, são segmentos de discurso constituídos pelo encadeamento de duas proposições, A (argumento) e C (conclusão), ligadas implícita ou explicitamente por conectores como portanto (donc) e no entanto (pourtant). Mas Ducrot refuta a interpretação de A (argumento) justificando C (conclusão), embora entenda que essa interpretação faça parte dos conhecimentos metalinguísticos dos falantes e constitua um nível incontestável da compreensão dos encadeamentos em portanto ou em no entanto. A ideia de base da teoria criada por ele e Anscombre, e desenvolvida por Carel, é que, nesses encadeamentos, o sentido do argumento A contém em si a indicação, ou a instrução, de que ele deve ser completado pela conclusão C. Em outras palavras, a teoria postula que em um encadeamento como Tu diriges depressa demais (A), tu corres o risco de sofrer acidente $(\mathrm{C})^{2}$, o sentido de $\mathrm{C}$ já está no segmento A: dirigir depressa demais significa velocidade perigosa. E, nesse sentido, a explicitação do conector é meramente ilustrativa. A prova disso é que para acessar o sentido constituído pelos dois segmentos não se precisa do conector.

Em relação à natureza dos encadeamentos, a teoria prevê que a significação de um termo não obriga a continuidade em portanto, possibilitando igualmente encadeamentos (combinações) em no entanto. Assim, um signo como longe pode encadear "É longe, vamos precisar de um meio de transporte", mas também "É longe, no entanto iremos a pé". Na teoria, os encadeamentos em portanto são ditos normativos; os encadeamentos em no entanto, transgressivos. É dessa forma que a ANL e a TBS postulam que tanto os encadeamentos normativos quanto os transgressivos já estão potencialmente previstos na língua.

Segundo Ducrot (2009, p. 21), essa definição de argumentação constituída pelo encadeamento de duas proposições pode ser estendida a encadeamentos que ligam não apenas duas proposições sintáticas, mas duas sequências de proposições, como dois parágrafos de um artigo. Desse modo, a ANL é uma teoria que oferece um aparato para a descrição das relações argumentativas que se estabelecem em diferentes níveis linguísticos e que são responsáveis pela construção de sentidos no discurso. A concepção de encadeamento procede de uma proposição saussuriana, a de relações sintagmáticas que já estão previstas na língua.

Ao discorrer sobre como teve contato com o estruturalismo e, mais especificamente, com o pensamento saussuriano, no artigo La sémantique argumentative peutelle se réclamer de Saussure? (DUCROT, 2006), Ducrot diz ter-se perguntado se ele se mantinha fiel a Saussure. A resposta é a de que em certos aspectos, não, mas enfatiza que isso não ocorre em relação à noção de valor, que ele sempre procurou colocar no centro do seu trabalho em semântica, com a ideia de "relação". Esse empréstimo

\footnotetext{
2 Este e outros exemplos são tirados dos próprios textos da teoria. Alguns com pequenas adaptações.
} 
é explicitado quando Ducrot (2006: 160-161) afirma que da mesma forma que Saussure introduziu no valor de um signo relações sintagmáticas, "in praesentia", o que significa dizer que a língua é um sistema em que todos os termos são solidários e podem combinar-se entre si, sua teoria postula que são as unidades língua que preveem certos tipos de encadeamentos e impedem outros. E são essas possibilidades de encadeamentos que constituem a significação das palavras e expressões na língua. A concretização dessas possiblidades pela atividade discursiva do falante resulta em enunciados, realizações sempre únicas, que contêm sentidos sempre singulares. Nesse contexto teórico, significação e sentido se diferenciam por referir, respectivamente, sistema e discurso, como se verá mais adiante.

Segundo Ducrot (2006), é preciso distinguir os encadeamentos que podem ser ligados a um signo por uma relação já prevista na língua (ditos encadeamentos "estruturais") daqueles cuja ligação com o signo depende de condições do discurso (denominados encadeamentos "contextuais"). A distinção entre esses dois tipos de encadeamento é mostrada, por ele, com o verbo perdoar, que tem, entre outras possibilidades, os encadeamentos estruturais "amar portanto perdoar" $\mathrm{e}$ "amar no entanto não perdoar". Ou seja, a palavra "amar" contém nela mesma essa significação ou possibilidade de encadeamento com "perdoar". Mas ele explica que esse mesmo verbo, também, possibilita encadeamentos "contextuais" do tipo "Estar de bom humor portanto perdoar" ou "Estar de mau humor no entanto perdoar", nos quais o sentido de "perdoar" não resulta da sua relação semântica com "amar", definindo-se somente no discurso, ou seja, nas combinações concretizadas. São combinações de palavras e expressões que não decorrem da significação que esses signos têm na língua como possibilidade, mas da combinação de palavras engendrada no uso da língua, no discurso.

Ainda a respeito do conceito de encadeamento, no artigo $O$ que é argumentar?, Carel (2005) qualifica de encadeamento argumentativo qualquer sequência de dois segmentos, de certo modo, dependentes um do outro. Trazendo exemplos da própria autora, em Faz calor; vamos sair e Faz calor; não vamos sair tem-se para "calor" sentidos diferentes, dado que o sentido de calor decorre da relação estabelecida entre os dois segmentos. Na primeira ocorrência, o calor é entendido como "um convite à saída"; na segunda, "um obstáculo". Ou seja, o sentido dos enunciados não está no signo "calor", mas resulta da relação que o segmento que contém calor

\footnotetext{
3 Esse exemplo ilustra a possibilidade de o encadeamento ser realizado à direita ou à esquerda. Neste caso, "perdoar" recebeu um encadeamento à esquerda. Nesse sentido seria possível pensar "perdoar" portanto amar e também "perdoar" no entanto não amar.
}

estabelece com o outro. Por essa perspectiva teórica, deve-se entender que as palavras da língua contêm a significação e que o sentido resulta dos encadeamentos que constituem os enunciados. A explicitação desses e outros conceitos fundantes constitui o tema da próxima seção

\section{Sobre a metodologia da ANL e conceitos básicos}

O percurso analítico previsto pela Teoria da Argumentação na Língua (e também pela Teoria dos Blocos Semânticos) vai do enunciado (do discurso) à língua (sistema). Ou seja, trata-se de uma teoria que procura descrever os sentidos dos enunciados para explicar o próprio funcionamento da língua em termos de produção de sentido. O observável, em outras palavras, o que pode ser descrito é o fato de um determinado enunciado poder ser interpretado como veiculando determinado sentido. Ou seja, a questão é explicar por que tal enunciado tem esse sentido e não outro.

Para dar conta desse percurso - da descrição dos sentidos do enunciado à explicação da significação na língua -, são empregados tanto termos que remetem a entidades abstratas quanto termos que referem entidades concretas. Entre os que referem entidades abstratas tem-se frase, texto, significação, língua; entre os que remetem a entidades concretas tem-se enunciado, discurso e sentido. Para entender o valor semântico de "sentido" e distingui-lo de "significação", a teoria adotou o conceito de "instrução". Uma instrução é entendida como uma orientação da própria língua em relação às possibilidades que um signo tem de se combinar com outro para produzir sentidos nos enunciados.

Segundo Ducrot (1984, p. 368), a terminologia adotada não possui nenhuma universalidade, mas visa apenas evitar algumas confusões que poderiam mascarar ou tornar insolúveis, ou mal compreendidos, problemas a abordar. Para ele, a decisão de que a determinado termo é atribuída determinada noção é arbitrária.

É assim que frase e texto, nos estudos ducrotianos, referem entidades abstratas ligadas ao sistema da língua, que é constituído de uma pluralidade de signos e de uma pluralidade de possiblidades de combinações, as regras da língua. .A frase é entendida como um constructo teórico e, como tal, abstrato. Ducrot diz chamar de frase o material linguístico de que o locutor se serve para produzir enunciados. O texto designa um conjunto de frases. Ambos, frase e texto, são dotados de significação que se constitui por um conjunto de instruções abertas e passíveis de análise. Os termos enunciado e discurso remetem à língua como atividade. O enunciado, como realização da frase por um locutor, é dotado de sentido. Um conjunto de 
enunciados ligados entre si pode constituir um discurso. Assim, frase e texto referem unidades do sistema linguístico e distinguem-se de enunciado e discurso que remetem ao uso da língua.

A terminologia adotada permite distinguir, segundo Ducrot (1984, p. 368), por um lado o material linguístico sempre idêntico em cada emprego e, de outro, as realizações (os enunciados) a que esse material dá lugar; realizações que são sempre únicas porque cada uma ocupa um lugar determinado no espaço e no tempo. Por essa concepção teórica, uma mesma frase poderá dar lugar a diversos enunciados, mas não se pode dizer que alguém proferiu várias vezes o mesmo enunciado. Repetida pelo mesmo locutor, mesmo que em sequência, a mesma frase produzirá sempre enunciados distintos.

Para melhor entender o conceito de instrução (que tem como equivalente o termo orientação), é preciso recorrer ao de significação, entendida, na teoria, como um conjunto de instruções que levam a constituir um conteúdo a partir de uma situação de enunciação. Pode-se exemplificar a ideia de instrução com a palavra "inteligente". Diz-se que ela contém em si mesma a instrução ou orientação para uma continuidade como "inteligente portanto encontrará a solução para o problema" ou "inteligente portanto será aprovado". Nesses encadeamentos, é a própria palavra "inteligente" que contém a ideia de "sucesso", que funciona como orientação para possibilidades de encadeamentos. Para "transgredir" essa orientação será preciso empregar um conector que explicite a transgressão, como no entanto. "Inteligente no entanto não será aprovado". A instrução é, então, uma espécie de regra que define possibilidades de combinar signos. A partir dessas instruções contidas na significação das palavras, o locutor cria sentidos, impondo pontos de vista. Diz-se, assim, que a língua disponibiliza signos isolados que esperam ser postos em combinação para a produção do discurso.

Outro conceito a que a teoria dá destaque é o de enunciação que, para Ducrot, constitui o evento, o fato que faz surgir um enunciado. Em outros termos, é pela enunciação que uma frase se realiza concretamente, transformando-se em enunciado. Em $O$ Dizer e o Dito (1987, p. 181-182), quando esboça sua teoria polifônica, Ducrot trata da descrição da enunciação que, segundo ele, é constitutiva dos sentidos dos enunciados. Essa descrição "contém, ou pode conter, a atribuição à enunciação de um ou vários sujeitos que seriam a sua origem". A tese que ele se propõe defender é a necessidade de distinguir entre esses sujeitos dois tipos de personagens: os enunciadores e os locutores. Ducrot distingue locutor (ser do discurso) de sujeito falante (ser empírico). Em relação à noção de locutor, ele distingue ainda "o locutor enquanto tal" (por abreviação L) do locutor enquanto ser do mundo. L é o responsável pela enunciação e é considerado unicamente por essa propriedade (1987, p. 188). Ele denomina como enunciadores os seres que se expressam através da enunciação, sem que para isso lhes sejam atribuídas palavras precisas. Enunciadores são pontos de vista, posições expressas pela enunciação. O estudo linguístico da origem desses diferentes pontos de vista constitui a Teoria Argumentativa da Polifonia.

\section{Teoria Argumentativa da Polifonia (TAP)}

Em Logique, Structure, Énunciation, capítulo VII, Ducrot (1989, p. 165) diz que foi lendo Bally, especialmente o início de Linguistique générale et linguistique française, que ele foi conduzido a esboçar uma teoria linguística da polifonia. Afirma que, embora Bally não tenha ido muito longe nessa direção, foi ele quem lhe abriu caminho. Ao trazer à discussão as noções de enunciação e polifonia, Ducrot diz querer quitar uma dívida de reconhecimento a Charles Bally, por ter assumido dele a teoria polifônica e a ideia de que, ao descrever a enunciação, o enunciado pode não somente fazer nele aparecer os pontos de vista dos sujeitos modais (enunciadores para Ducrot), mas ele pode também lhe atribuir um responsável (sujeito comunicante para Bally e locutor para Ducrot) que não é o produtor efetivo das palavras (DUCROT, 1989, p. 185).

A teoria polifônica da enunciação aparece, inicialmente, no último capítulo de $O$ Dizer e o Dito (publicado em 1984), é posteriormente atualizada por ele e Marion Carel e continua em constantes revisões em estudos conduzidos atualmente por ela. Em Polifonia e Argumentação (CAREL, 2010), a autora deixa claro que ela trata de uma polifonia discursiva que se afasta em alguns aspectos da polifonia linguística construída por Ducrot. Em um texto mais recente, Théorie Argumentative de la Polyphonie (20012), ela apresenta os instrumentos de análise semântica que utiliza, a Teoria Argumentativa da Polifonia (TAP) e a Teoria dos Blocos Semânticos (TBS).

No artigo Atualização da Polifonia (2010) Carel e Ducrot retomam a ideia central da polifonia que, segundo eles, no decurso das discussões se embotou um pouco. Os autores $(2010$, p. 12) dizem tentar construir uma teoria polifônica mais fiel à intuição original de $O$ Dizer e $O$ Dito, mesmo se distanciando da proposta original em pontos essenciais. Para isso, eles propõem descrever os elementos constitutivos da significação, suas moléculas, como tripés: uma atitude do locutor do enunciado, um conteúdo, um enunciador. O propósito, dizem, é o de fazer coexistir, na concepção de polifonia, ao menos na maior parte dos casos, um locutor, sujeito único ao qual são atribuídas as atitudes frente aos conteúdos e aos enunciadores (CAREL; DUCROT, 2010, p. 13). 
Para os pesquisadores, a especificação da instância dita "enunciador" é a mais complicada, e tecem uma longa discussão em torno do tema. De acordo com os autores, a ideia central da concepção polifônica é a de "colocar na significação, ao lado das atitudes do locutor e dos conteúdos, uma terceira instância que, como as duas outras, não é do tipo referencial e que não pode ser vista como alusão a indivíduos" (2010, p. 21). Essa instância, a dos enunciadores, definiria um certo modo de garantir o dito.

Em outro artigo, Polifonia e argumentação, Carel (2010, p. 23) explicita um quadro enunciativo geral, no qual admite que qualquer enunciado possui um autor responsável pela introdução de diversos conteúdos. $\mathrm{Na}$ teoria, esse autor denomina-se locutor e é distinto do sujeito falante. A pesquisadora diz admitir também que os conteúdos dos enunciados podem ser introduzidos de diversas "maneiras de dizer", que são descritas por meio de dois parâmetros: a atitude discursiva e a Pessoa.

Por meio da atitude discursiva, o locutor indica o papel que ele dá em seu discurso ao conteúdo introduzido, ou seja, ele pode defender, ilustrar ou comentar o conteúdo. O conteúdo pode não ser discutido, simplesmente acordado ou ser excluído. Para Carel, essas atitudes do locutor são puramente discursivas e não psicológicas. (Esse esclarecimento é reiterado nos diferentes textos sobre o tema.) As atitudes discursivas indicam o papel que o conteúdo terá no discurso.

A noção de Pessoa é derivada daquela de enunciador (proposto por Ducrot em $O$ Dizer e o Dito). Os enunciadores ou Pessoas não são indivíduos particulares, mas funções discursivas. E, segundo Carel, parecem ter duas funções: a de indicar o ângulo de vista (como em segundo seu médico, Pedro vai bem) e a de indicar o que garante a validade do conteúdo. Em relação ao ângulo de vista, note-se que ter o médico como enunciador significa que a saúde de Pedro é a que um médico qualifica de boa. Expressões como ao ver de, segundo (entre tantas outras que indicam o ângulo de vista) obrigam a "leituras atributivas"; por elas o locutor introduz ângulos de vista que relativizam os conteúdos apresentados pelos enunciados que as contêm. Relativizar os conteúdos de um enunciado significa atribuir-lhe o sentido que é definido pelo ângulo de vista pelo qual esse conteúdo é apresentado, como no exemplo acima: a saúde de Pedro é a que é atribuída pelo médico.

Por Pessoa pode-se entender a voz da opinião pública (que em português pode ser representada sintaticamente pelo SE, marca de impessoalidade) e a voz dos fatos (como em Faz bom tempo), que Carel denomina voz do MUNDO. Quando o enunciado contém uma expressão como a meu ver (lexema de primeira pessoa do singular), o locutor é, ao mesmo tempo, o locutor e a Pessoa.
No desenvolvimento do texto Polifonia e argumentação (2010), Carel vai mostrando as dificuldades que as teorias polifônicas encontram ao analisar as unidades de um discurso fechadas em si mesmas. Descrever o sentido de duas proposições de um mesmo enunciado, independentes uma da outra, pode produzir um esfacelamento de sua unidade intuitiva. Como solução, aponta para uma concepção argumentativa do sentido, ou seja, para a possibilidade de descrever os enunciados pela Teoria dos Blocos Semânticos.

No início do artigo Polifonia Linguística, Carel (2011) traz uma distinção entre duas formas de teoria polifônica: a polifonia semântica e a polifonia intertextual. A primeira liga-se ao nome de Ducrot e diz respeito à alusão, por um único enunciado, a vários conteúdos (é o caso, entre outros, do enunciado negativo, como em "parou de fumar", que contém o pressuposto "fumava antes"); a segunda forma de polifonia liga-se a Bakhtin e diz respeito à presença de várias instâncias enunciadoras no interior da enunciação, instâncias que representam vozes distintas e independente do locutor.

Ao fazer essa distinção, autora mostra que a polifonia da qual ela trata, a polifonia semântica, foca os conteúdos dos enunciados pelo linguístico (e não pela enunciação). Ela explica, com exemplos, que os vários conteúdos estão prefigurados na significação da frase enunciada e o locutor toma posição em relação a esses conteúdos, que podem ser de concordância, de exclusão, de ilustração e outros: "[...] as vozes da polifonia semântica são usadas pelo locutor para graduar sua própria responsabilidade em relação ao conteúdo introduzido: trata-se, para Ducrot, de representar só a enunciação do locutor sob suas diferentes formas" (CAREL. 2011, p. 32) ${ }^{4}$.

Em La Théorie Argumentative de la Polyphonie (2012), Carel faz uma apresentação detalhada da Teoria Argumentativa da Polifonia (TAP) e da Teoria dos Blocos semânticos (TBS). No início do texto, ela esclarece que a TAP se inscreve na família de teorias que têm por objeto a enunciação, ou seja, o fenômeno próprio ao enunciado, que tem sido descrito tradicionalmente, segundo a autora, de maneira negativa, por englobar indicações do tipo falso, verdadeiro, necessário, provável.

A TAP, da mesma forma que a Teoria da Argumentação na Língua (ANL), rejeita a hipótese das teorias enunciativas clássicas segundo as quais se deve sempre isolar, no sentido de um enunciado, uma descrição do mundo avaliável em termos de verdadeiro e falso. Da mesma forma, a TAP e a ANL rejeitam a hipótese de que a enunciação descreve o estado psicológico de um indivíduo, o sujeito falante ou outro; mais exatamente,

\footnotetext{
4 Carel, na sequência, diz não crer nessa possiblidade defendida por Ducrot. Ela propõe, como alternativa, descrever os elementos da significação, suas moléculas como tripés. Descrição que aparece em Carel (2010).
} 
essas abordagens rejeitam a ideia de que a enunciação comunica aquilo que o locutor apresenta como sendo seu estado psicológico ou aquele de um outro. A teoria diz que o locutor pode mentir ou se enganar sobre a natureza desse estado psicológico. Fica assim, reafirmado que a polifonia de que se ocupam Carel e Ducrot trata sempre de entidades linguísticas e não de indivíduos.

Segundo Carel, a TAP propõe preservar a dicotomia dos sentidos entre um "conteúdo" e a "colocação desse conteúdo em discurso" (la mise en dircours). Para manter essa dicotomia, a autora propõe repartir as tarefas entre duas teorias: a TAP que é uma teoria da "colocação do conteúdo em discurso"; a TBS que é uma teoria de "conteúdo", quer dizer, uma teoria que se ocupa daquilo que é colocado em discurso. Inscrita no quadro geral da Teoria da Argumentação na Língua, a TBS descreve as palavras, os grupos de palavras, os enunciados pelos discursos argumentativos que essas unidades evocam.

Sobre a colocação de um conteúdo em discurso, a autora afirma que essa atividade é descrita pela TAP por duas indicações: uma relativa à "função textual" do conteúdo e outra ao "modo de aparição" desse conteúdo (CAREL, 2012, p. 13). Ela exemplifica as duas indicações com os seguintes enunciados: "Eu acho este sermão monótono" e "Este sermão é monótono". Ambos os locutores declaram que o conteúdo (este sermão é monótono) é constitutivo do seu posicionamento, mas só o primeiro se implica (s 'investit) na sua enunciação. Nos dois casos, segundo a autora, o conteúdo tem a mesma função textual, mas ele aparece sob modos diferentes: no primeiro caso, o locutor se coloca na enunciação, o que não ocorre no segundo. Para Carel, este é um fenômeno central para a TAP.

A função textual, primeiro constituinte da "colocação de um conteúdo em discurso", pode assumir três formas: um conteúdo pode ser "assumido", "acordado" ou "excluído". São as principais atitudes que o locutor pode tomar frente a um conteúdo. As duas primeiras funções são concebidas como positivas, no sentido de que um conteúdo "assumido" ou "acordado" não pode ser objeto de contradição na continuidade do discurso. Trata-se, nos dois casos, de conteúdos afirmados, mas só o primeiro torna-se objeto do enunciado e é colocado em destaque. O segundo, o conteúdo "acordado", não dá margem a nenhum desenvolvimento, inscrevendo-se num plano de fundo. $\mathrm{O}$ exemplo de base da oposição entre as duas funções textuais é a distinção que se faz entre o posto e o pressuposto linguístico ${ }^{5}$. Ainda, segundo a autora (2012, p. 14), um conteúdo "acordado" não aparece nunca isolado e está enunciativamente subordinado a um conteúdo "assumido". A exclusão constitui a terceira forma da função textual e se distingue das duas anteriores por ser negativa. Na sequência do enunciado que comporta uma exclusão, o locutor se engaja em não afirmar o conteúdo "excluído". Como os conteúdos "acordados", os conteúdos "excluídos" são dependentes de um conteúdo "assumido", com o qual constituem um único motivo enunciativo (2012, p. 15).

Em relação ao segundo constituinte da "colocação de um conteúdo em discurso", ou modo de aparição desse conteúdo, Carel (2012, p. 18) lembra que enunciar um conteúdo não é apenas dar-lhe uma função textual. Os conteúdos são expressos sob um certo tom; eles aparecem sob um certo modo. A TAP os descreve por meio de uma Pessoa Enunciativa e são atrelados a um conteúdo e à indicação da função textual, na qual se distinguem a Pessoa do Mundo, a do Locutor e a do Ausente o ELE (l'Absent IL).

Essas Pessoas Enunciativas, segundo Carel, lembram os enunciadores de Ducrot explicitados na primeira proposta de $O$ Dizer e o Dito. Como ele, a autora insiste no fato de que não se trata de indivíduos que seriam fontes dos conteúdos comunicados, mas de seres "míticos" em número restrito. São pessoas discursivas que representam o modo de apresentação dos conteúdos. Segundo Carel, essas Pessoas podem ser comparadas às duas formas enunciativas de Benveniste: a Pessoa do Locutor e a Pessoa do ausente (o ELE) são realizações da enunciação discursiva; a Pessoa do Mundo é uma realização da enunciação histórica.

Para Carel (2012, p. 20), a Pessoa (ou voz) do Mundo é aquela através da qual são apresentados os conteúdos de enunciados factuais, em enunciados que parecem "contar-se a si mesmos" (Benveniste), descolados de qualquer subjetividade. Carel e Ducrot (2010, p. 20) distinguem a Pessoa Mundo em enunciados que dizem alguma coisa porque "as coisas são assim". São exemplos standard desse tipo de enunciados os que contêm verbos no passado simples. Para os autores, muitos enunciados científicos $^{6}$, sobretudo na boca dos não científicos, são desse tipo; também é desse tipo um grande número das nossas afirmações cotidianas.

A segunda forma de desinvestimento enunciativo, entendido como menor ou não implicação da subjetividade no enunciado, é marcada pela voz da Pessoa Ausente. Carel distingue, ainda, um desinvestimento não factual de um factual. Este último produz a Pessoa do Mundo, descrita acima. O desinvestimento não factual (Pessoa Ausente) marca-se por meio de locuções como "parece que" (il semble que, il paraît que). O locutor de um enunciado que assume essa forma se desinveste de seu enunciado e o conteúdo aparece como recebido. Carel insiste no fato

\footnotetext{
5 Conceito exaustivamente discutido em O dizer e o Dito.

6 Foi essa afirmação que motivou a busca, na teoria, de elementos que possam contribuir para a explicitação do modo de aparição dos conteúdos de textos acadêmicos/científicos
} 
de que a Pessoa Ausente marca um desinvestimento não factual do locutor e não um discurso reportado, do qual o locutor tira a fonte.

Carel (2012, p. 26) conclui o texto, dizendo que a TAP se inspira em trabalhos de Benveniste que distingue radicalmente os fenômenos enunciativos de questões de fontes, mas que conserva dos trabalhos de Ducrot a hipótese (ausente nos trabalhos de Benveniste) de que um sujeito falante se exprime somente de maneira fragmentária, através de múltiplas máscaras. Ela salienta, sobretudo, que a TAP retém de Ducrot a distinção entre o sujeito falante e a Pessoa Enunciativa. Desse modo, um locutor pode afirmar ou assumir um conteúdo, tornando-o objeto de sua fala, sem se colocar ele mesmo na origem do conteúdo.

Como na proposição inicial de Ducrot - "Esboço de uma teoria polifônica da Enunciação" - (Cap. VIII, de $O$ Dizer e o Dito), a TAP admite a distinção entre o sujeito falante, na origem da existência material do enunciado, e o locutor enquanto tal, o locutor L, que tem sob sua responsabilidade a função textual dos conteúdos e seus empregos.

\section{A teoria polifônica como instrumento de análise semântica}

Perguntado sobre quais seriam os aspectos da linguagem para os quais os jovens linguistas deveriam voltar suas pesquisas atualmente, em entrevista concedida a Antônio Carlos Xavier (2012), Oswald Ducrot responde que jovens linguistas devem estudar tudo o que se refere ao discurso. Mas há na resposta de Ducrot uma passagem que revela explicitamente sua preocupação como o estudo da língua:

Tudo o que concerne à enunciação deve ser atualmente objeto de atenção dos jovens linguistas. Todavia, é preciso igualmente continuar a estudar a matéria mesmo da língua, estudar a palavra, a gramática, estudar o modo como as palavras se organizam nas frases, não procurar fazer estudos aéreos, fora da realidade, eles devem entrar na realidade da língua e ver os problemas de sintaxe... (Entrevista, 2012). (grifo acrescido)

Estudar a enunciação, todavia continuar a estudar a matéria mesmo da língua, estudar a palavra, a gramática. Essa parece ser a primeira grande lição para os que escolhem seguir os passos da sua teoria.

Embora incipiente ainda, o presente estudo tem o objetivo de buscar na Teoria Argumentativa da Polifonia, decorrente da Teoria da Argumentação na Língua, elementos que possam contribuir para a explicitação dos modos de aparição dos conteúdos e dos sentidos produzidos, por esses modos, em textos acadêmicos, também ditos científicos (artigos, dissertações, teses), nos quais o locutor, responsável pelo conteúdo acionado, mobiliza uma diversidade de enunciadores.

Como ponto de partida para a descrição de enunciados dessa natureza, assume-se da teoria o pressuposto da coexistência de um locutor único responsável pelas atitudes frente aos conteúdos e aos enunciadores evocados na produção de um enunciado, indiretamente assumindo, concordando ou excluindo a voz que carrega o conteúdo e o garante. Como em enunciados científicos é comum a mobilização de uma multiplicidade de instâncias enunciativas, porque há normalmente uma multiplicidade de conteúdos evocados, a responsabilidade do locutor é complexa. Daí decorre a necessidade da descrição e decomposição dessas instâncias, de seus conteúdos e de seus modos de organização. Para isso, a TAP parece apresentar-se como instrumento de análise semântica capaz de dar conta da complexidade envolvida em enunciados desse tipo.

Para descrever as diversas formas de introduzir os conteúdos, as "maneiras de dizer", a TAP propõe dois parâmetros: a atitude discursiva e a Pessoa. Por meio da atitude discursiva, o locutor indica o papel que ele dá em seu discurso ao conteúdo introduzido, ou seja, o locutor pode defender, ilustrar ou comentar o conteúdo. Um conteúdo pode não ser discutido, simplesmente acordado ou ser excluído. A noção de Pessoa deriva, com se viu, daquela de enunciador de Ducrot. Os enunciadores ou Pessoas não são indivíduos particulares, mas funções discursivas. E, segundo Carel, parecem ter duas funções: a de indicar o angulo de vista e a de indicar o que garante a validade do conteúdo. Avaliar um texto por essas duas categorias - a atitude discursiva e a Pessoa - parece ser uma possibilidade de melhor compreender os sentidos dos enunciados que constituem os discursos acadêmicos.

A distinção entre um sujeito falante, na origem da existência material do enunciado, e o locutor enquanto tal (o Locutor L), ser discursivo que indica um modo de apresentação dos conteúdos e assume a responsabilidade da função textual e o emprego desses conteúdos, conduz a uma análise mais centrada na língua e, como tal, mais fiel à teoria que orienta no sentido de "estudar a matéria mesmo da língua, estudar a palavra, a gramática, estudar o modo como as palavras se organizam nas frases, não procurar fazer estudos aéreos, fora da realidade", no dizer acima referido de Ducrot.

Para os fins a que se propôs este estudo, buscar instrumentos para a análise semântica do discurso acadêmico, o percurso realizado revela o potencial da TAP para esse fim, mais especificamente, em duas indicações de análise: uma relativa à "função textual" do conteúdo, outra ao "modo de aparição" desse conteúdo no enunciado. 
Enfim, o estudo da ANL, que tem continuidade na TAP e na TBS (essa última não explorada neste artigo), conduz à compreensão de que "falar consiste, não em nomear, mas em relacionar as palavras em frases, em parágrafos, em textos, de modo que a descrição de uma palavra permita a descrição dos enunciados em que está empregada" (CAREL, 2009, p. 26). Entender e explicar como essas relações engendram sentidos é tarefa do linguista, mas também daqueles que, mais modestamente, querem apenas conhecer melhor a natureza de seu objeto de aprendizagem ou de ensino, a língua.

\section{Referências}

CAREL, Marion. La Théorie Argumentative de la Polyphonie. In: BOURMAYAN, Anouch; CÁMPORA et al. Magdalena; Argumentation et Polyphonie: de Saint Augustin à RobbeGrillet. Paris: L'Armattan, 2012. p. 7-55.

CAREL, Marion. A Polifonia Linguística. Letras de Hoje, Porto Alegre, v. 46, n. 1, p. 27-36, jan.-mar. 2011.

CAREL, Marion; DUCROT, Oswald. Atualização da polifonia. Desenredo, Revista do Programa de Pós-Graduação em Letras da Universidade de Passo Fundo, v. 6, n. 1, p. 9-21, jan.-jun. 2010
CAREL, Marion. Polifonia e Argumentação. Desenredo, Revista do Programa de Pós-Graduação em Letras da Universidade de Passo Fundo, v. 6, n. 1, p. 22-36, jan.-jun. 2010.

CAREL, Marion. Análise argumentativa do léxico: o exemplo da palavra 'medo'. Letras de Hoje, Porto Alegre, v. 44, n. 1, p. 26-35, jan./mar. 2009.

CAREL, Marion. O que é argumentar? Desenredo, Revista do Programa de Pós-Graduação em Letras da Universidade de Passo Fundo, v. 1, n. 2, p. 77-84, jul.-dez. 2005.

DUCROT, Oswald. Logique, Structure, Énunciation: lectures sur le langage. Paris: Les Éditions de Minuit, 1989.

DUCROT, Oswald. La sémantique argumentative peut-elle se réclamer de Saussure? In: Nouveaux regards sur Saussure: Mélanges offerts à Rene Amacker. Edités par Louis de Saussure. Genève: Librairie Droz, 2006.

DUCROT, Oswald. Argumentação retórica e argumentação linguística. Letras de Hoje, Porto Alegre, v. 44, n. 1, p. 20-25, jan.-mar. 2009.

XAVIER, Antônio Carlos. Trajetória e legado de um filósofo da linguagem: Oswald Ducrot. Entrevista realizada e traduzida por Antônio Carlos Xavier. Revista Investigações, v. 25, n. 2, jul. 2012.

Recebido: 19 de agosto de 2015

Aprovado: 03 de novembro de 2015

Contato: neiva_gomes@uniritter.edu.br 